\title{
EPA's CLEAN POWER PLAN: IMPLEMENTATION OPTIONS SURVEY RESULTS
}

INSIGHTS FROM INDUSTRY EXPERTS AND STATE OFFICIALS ON IMPLEMENTATION OF EPA'S CLEAN POWER PLAN

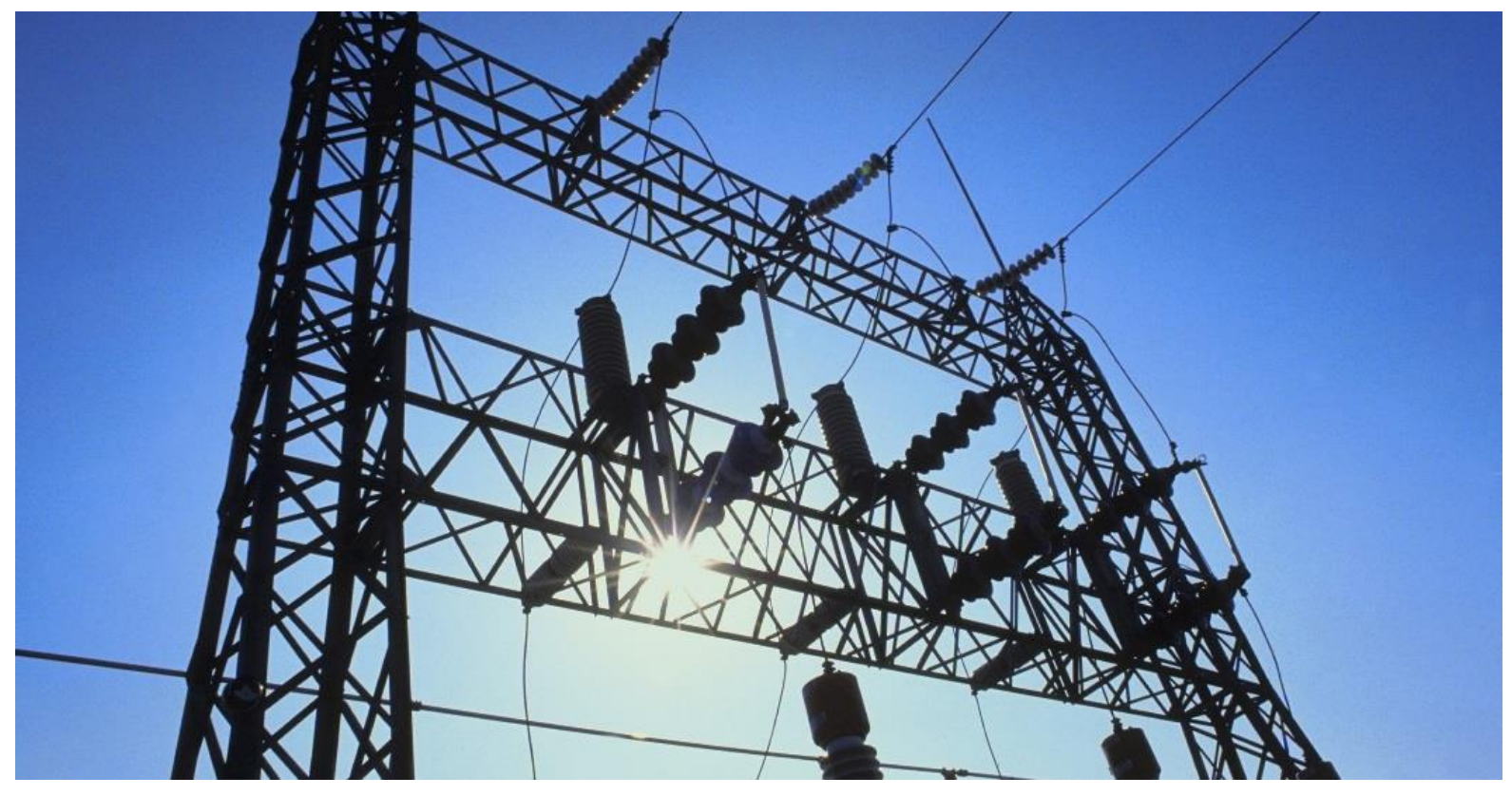

MELINDA TAYLOR AND ROMANY WEBB

JUNE 2015

The University of Texas at Austin

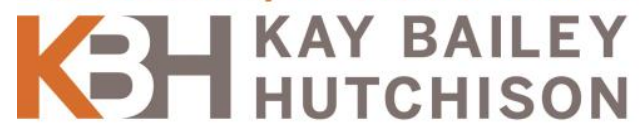

CENTER FOR ENERGY, LAW \& BUSINESS" 



\section{EPA's Clean Power Plan: Implementation Options Survey Results}

Research Paper No. 2015-02

June 2015

AUTHOR

Melinda Taylor and Romany Webb

\section{PRESENTED BY}

Kay Bailey Hutchison Center for Energy, Law, and Business

University of Texas School of Law and McCombs School of Business

727 East Dean Keeton Street

Campus Mail Code: D1800

Austin, TX 78705

(512) 232-1408

http://kbhenergycenter.utexas.edu

(C) 2015 All rights reserved 


\section{About the KBH Energy Center}

The Kay Bailey Hutchison Center for Energy, Law, and Business is an innovative interdisciplinary joint venture of the School of Law and McCombs School of Business at The University of Texas at Austin. The mission of the $\mathrm{KBH}$ Energy Center is to provide the finest educational opportunities in the United States to students who wish to pursue careers in energy and to serve as a nexus for incisive, unbiased, and relevant research and analysis for policymakers, with special emphasis on Latin America.

\section{About the Authors}

Melinda Taylor is a senior lecturer at the School of Law and the executive director of the $\mathrm{KBH}$ Energy Center. Prior to joining the faculty, Melinda was the director of the Ecosystem Restoration Program at the Environmental Defense Fund, where she worked to protect endangered species and water resources. She has also served as deputy general counsel of the National Audubon Society and was an associate at Bracewell \& Patterson in Washington, D.C.

Romany Webb is a post-graduate research fellow in the KBH Energy Center. Romany's current research focuses on controlling greenhouse gas emissions from energy production. Romany previously worked at the University of California, Berkeley, where she researched climate change policy. She has also practiced energy and water law in Sydney, Australia.

\section{Acknowledgements}

The authors would like to thank Thomas McGarity and David Spence at The University of Texas School of Law for their insightful comments on this report.

The authors also thank the following University of Texas students for their assistance in conducting the surveys on which this report is based:

Sarah Ball

Neha Chaudhary

Darcia Datshkovsky Sáenz

Ukamaka Enwerem

Alexandra Gullett

Cristina Lomanto 


\section{Sachidanand Sahoo}

Janani Srinivasan

We are also grateful to Christopher Van Atten and Kim Voellmann of M.J. Bradley \& Associates LLC for their advice on the design and administration of the survey.

Funding for the survey was generously provided by the Energy Foundation. 


\section{EXECUTIVE SUMMARY}

On June 2, 2014, the U.S. Environmental Protection Agency (EPA) proposed a plan to reduce carbon dioxide $\left(\mathrm{CO}_{2}\right)$ emissions from existing fossil fuel power plants based on its authority under section 111(d) of the Clean Air Act (42 U.S.C. $\S 7411(\mathrm{~d})$ ). ${ }^{1}$ The proposal, known as the Clean Power Plan or 111 (d) rule, will require each state to develop a plan for reducing the rate of $\mathrm{CO}_{2}$ emissions from its electric power system. As currently proposed, the Clean Power Plan requires states to meet interim emissions reduction targets beginning in 2020, with final targets to be achieved by 2030 .

The Clean Power Plan envisages that electric power companies will reduce their emissions by, among other things, switching to lower carbon fuel sources and increasing investment in energy efficiency. Currently, coal supplies approximately 40 percent of the electricity delivered to the grid in the U.S. ${ }^{2}$ Reducing the carbon intensity of the electric power system will mean increased reliance on natural gas and alternative sources of power, such as nuclear, wind, and solar. To some extent, this transition is already underway, even in the absence of federal standards. The U.S. Energy Information Administration estimates that, between 2004 and 2014, coal-fired electricity generation declined by nearly 20 percent. ${ }^{3}$ Over the same period, natural gas-fired generation increased by almost 58 percent and non-hydroelectric renewable generation by over 200 percent. $^{4}$

The Clean Power Plan promises to accelerate this transition away from coal towards natural gas and renewables. Given this, the Clean Power Plan has been highly controversial. EPA received approximately two million public comments from states, industry leaders, environmental groups, and public citizens with a wide range of opinions on the best options to proceed with the Clean Power Plan.

To help inform the on-going policy debate, from April to June 2015, the Kay Bailey Hutchison Center for Energy, Law, and Business at The University of Texas at Austin conducted a survey on key aspects of the Clean Power Plan. 66 valid survey responses were received. The survey respondents included power company executives, industry consultants, state environmental officials, state energy officials, utility regulator staff, and regional transmission organization staff from various locations. Responses were not collected from every state.

Survey respondents were not asked whether they support or oppose the Clean Power Plan. Rather, the survey focused on issues relating to implementation of the Plan. The survey results are summarized in this report. 


\section{KEY FINDINGS}

- The overwhelming majority of survey respondents favored the development of state compliance plans rather than federally-developed plans.

- There was broad support, among survey respondents, for mass-based trading programs. Support was found in both Democratic- and Republican-controlled states but was higher in the former than the latter.

- Survey respondents were divided on the use of renewable portfolio standards and energy efficiency measures. These policies were popular among energy and environmental officials, particularly in Democratic-run states. However, few power company executives supported use of the policies.

- Most survey respondents favored market-based compliance options. 68 percent of respondents indicated that they preferred mass-based trading over other market-based options. 11 percent of respondents listed rate-based trading as their preferred option.

- Almost two-thirds of survey respondents favored adoption of mass-based emissions targets, arguing that they are easier to implement than the rate-based targets proposed by EPA. Others, however, expressed concern about the difficulties of converting any rate-based target into a mass-based form. There was also some concern about a mass-based target's perceived limits on future electricity growth.

- The bulk of survey respondents supported interstate cooperation on the Clean Power Plan, with 90 percent arguing that states should develop multi-state plans or single-state plans that preserve the option to trade across state lines. 


\section{INTRODUCTION}

On June 2, 2014, the U.S. Environmental Protection Agency (EPA) proposed carbon pollution standards for existing fossil fuel power plants. ${ }^{5}$ The proposal, commonly known as the Clean Power Plan, aims to reduce nationwide carbon dioxide $\left(\mathrm{CO}_{2}\right)$ emissions from the power sector by 30 percent below 2005 levels by $2030 .{ }^{6}$ To that end, the Clean Power Plan sets binding emissions reduction targets for each state. ${ }^{7}$ The states must reduce their annual $\mathrm{CO}_{2}$ emissions rates - the amount of emissions per unit of power produced - by between 11 and 72 percent.

The proposed Clean Power Plan does not prescribe how the states are to achieve their respective emissions reduction targets. Rather, it envisages that each state will develop its own plan, outlining its preferred method of reducing emissions. ${ }^{8}$ This report presents the views of industry participants and state officials on key implementation issues facing the states. The report does not take a position for or against the Clean Power Plan; nor does it advocate any particular means of implementing the Plan. Rather, it is intended as an impartial analysis of industry attitudes towards implementation.

\section{Statutory Framework for the Clean Power Plan}

In developing the Clean Power Plan, EPA relied on its statutory authority to regulate new and existing stationary sources of air pollution under the Clean Air Act (42 U.S.C. Ch. 7401 et seq.). Clean Air Act, section 111(b)(1)(A) (42 U.S.C. § 7411(b)(1)(A)) requires the EPA administrator to publish a list of categories of stationary sources which, in his/her judgment, cause or contribute significantly to "air pollution which may reasonably be anticipated to endanger public health or welfare." In 2009, the administrator determined that emissions of $\mathrm{CO}_{2}$ and five other greenhouse gases endanger public health and listed fossil fuel power plants as a source of those emissions. $^{9}$

Clean Air Act, section 111(b)(1)(B) (42 U.S.C. § 7411(b)(1)(B)) requires EPA to establish standards of performance (known as new source performance standards or NSPS) for new sources in any listed category. Fulfilling this requirement, in September 2013, EPA proposed NSPS for $\mathrm{CO}_{2}$ emissions from new fossil fuel power plants. ${ }^{10}$ These NSPS are expected to be finalized by EPA by summer of $2015 .{ }^{11}$ At the same time, EPA will also finalize pollution standards for existing fossil fuel power systems. ${ }^{12}$

Under Clean Air Act, section 111(d)(1) (42 U.S.C. $\S 7411(d)(1)$ ), when NSPS are issued with respect to an air pollutant (other than a criteria pollutant or hazardous air pollutant), EPA must establish regulations to address emissions of that pollutant from existing sources which would be subject to the NSPS if they were new sources. These regulations take the form of emissions guidelines, which the states must follow in developing plans to reduce air pollution. ${ }^{13}$ For each 
state, the guidelines specify an emissions reduction target, reflecting "the degree of emissions limitations achievable through the application of the best system of emission reduction which (taking into account the cost of achieving such reduction and any non-air quality health and environmental impact and energy requirements) the administrator determines has been adequately demonstrated."14

The proposed Clean Power Plan puts forward state-specific targets for reducing $\mathrm{CO}_{2}$ emissions from existing fossil fuel power plants. ${ }^{15}$ The targets were calculated based on four building blocks, which together represent the best system of emission reduction. These are:

1. reducing the carbon intensity of existing fossil fuel power plants through a six percent improvement in coal-unit heat-rates;

2. switching from the most carbon-intensive coal-fired and oil/gas-fired steam power plants to combined-cycle natural gas plants, with a target utilization rate of 70 percent;

3. reducing fossil fuel power generation by expanding renewable energy capacity nationally to 13 percent of total energy output and retaining 5.8 percent of nuclear generation at risk for retirement and nuclear generation under construction; and

4. using demand-side energy efficiency to produce cumulative national energy savings of 10.7 percent of 2012 load by 2030. ${ }^{16}$

EPA calculated the emissions reduction achievable by each state through application of these four building blocks. The building blocks were applied on a state-by-state basis, taking into account each state's resource mix, clean energy policies, and other factors.

\section{Achieving the State Emissions Reductions Targets}

The proposed Clean Power Plan does not prescribe how the states are to comply with their respective emissions targets. Rather, EPA envisages that each state will develop its own compliance plan, which can be tailored to its unique conditions. EPA has given the states significant discretion to formulate plans as they see fit:

- A state may elect to translate the rate-based emissions target into a mass-based standard. ${ }^{17}$ This would require the state to cap total annual $\mathrm{CO}_{2}$ emissions from all power plants. In contrast, a state adopting a rate-based target would have to reduce the amount of carbon dioxide its power sector emits per megawatt hour (MWh).

- States may use the building blocks identified by EPA to meet their emissions targets. The states are not, however, required to apply the building blocks in the same manner as the EPA did in setting the targets, nor are they limited to actions in the building blocks. Thus, a state may choose to place greater emphasis on one building block and less on 
another. ${ }^{18}$ Moreover, a state may also adopt other emissions reduction strategies not encompassed within the building blocks. ${ }^{19}$

- A state may make existing fossil fuel power plants "fully and solely responsible for achieving" the emissions targets. ${ }^{20}$ Alternatively, the state may adopt a portfolio approach, whereby power plants and other entities share responsibility for achieving the targets. ${ }^{21}$

- States may work together to comply with the Clean Power Plan and, for this purpose, may develop multi-state compliance plans. ${ }^{22}$

\section{Moving Forward with the Clean Power Plan}

EPA is expected to finalize the Clean Power Plan in summer 2015. The states will then have one or two years ${ }^{23}$ to develop plans for reducing emissions in accordance with the Plan. ${ }^{24}$ The states will have significant discretion in terms of the emissions reduction strategies they can adopt. To better understand how the states may exercise that discretion, and to inform EPA's rule-making process, The University of Texas at Austin conducted a survey on key aspects of the Clean Power Plan. The survey was completed by 66 respondents, including power company executives, industry consultants, state officials, ${ }^{25}$ and regional transmission organization (RTO) staff. Their responses are summarized in this report. 


\section{About the survey}

\section{Demographics}

Students from The University of Texas at Austin contacted 300 individuals to administer a short survey on the Clean Power Plan. Survey respondents were identified based on the contacts listed in public comments to the EPA in the Clean Power Plan docket, online directories of state energy and environmental officials, and outreach to industry experts.

66 valid survey responses were collected (i.e., a response rate of approximately 22 percent). Respondents consisted of power company executives, state officials, RTO staff, and industry consultants.

The power company executives surveyed work for a variety of organizations, under both public and private ownership. Approximately 71 percent of the executives reported that their organization owns or operates fossil fuel power plants that may be subject to regulation under the Clean Power Plan. ${ }^{26}$ Their answers did not differ significantly from those of other power company executives, whose organizations do not own or operate fossil fuel plants.

The survey did not collect responses from power company executives and/or other industry participants in every state. The respondents did, however, come from a geographically diverse area.
Who did this survey reach?

Power Company Executives - 24 (36\%)

State Officials - $28(42 \%)$

RTO Staff - 1 (2\%)

Industry Consultants - 13 (20\%)

Power Company Executives:

Investor Owned Utility - 11 (46\%)

Municipally Owned Utility -6 (25\%)

Cooperative Utility - 1 (4\%)

Independent Power Producer - 5 (21\%)

Other $-1(4 \%)$

State Officials:

Environmental Officials - 17 (77\%)

Democratic-run states - 9 (53\%)

Republican-run states -8 (47\%)

Energy Officials- 5

Democratic-run states - 2 (40\%)

Republican-run states - 3 (60\%)

Utility Regulator Staff - 6

Democratic-run states -2

Republican-run states -4 
Power Company Executives

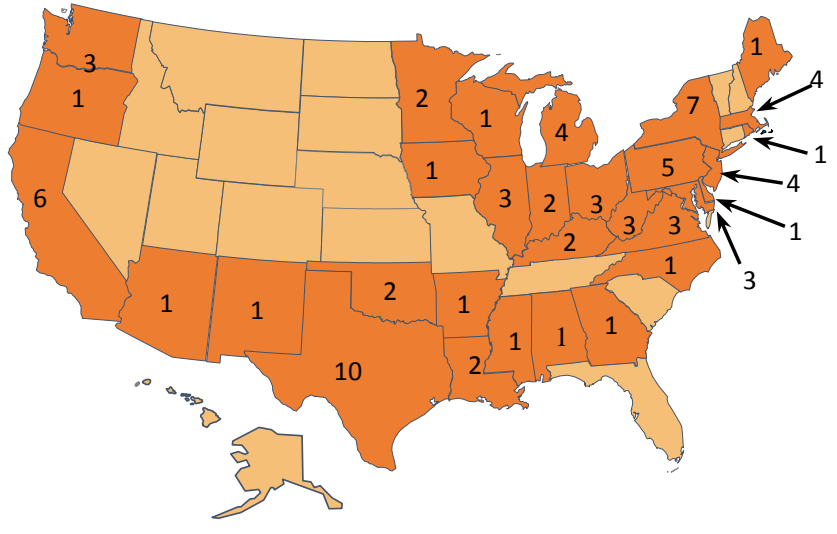

\section{State Officials}

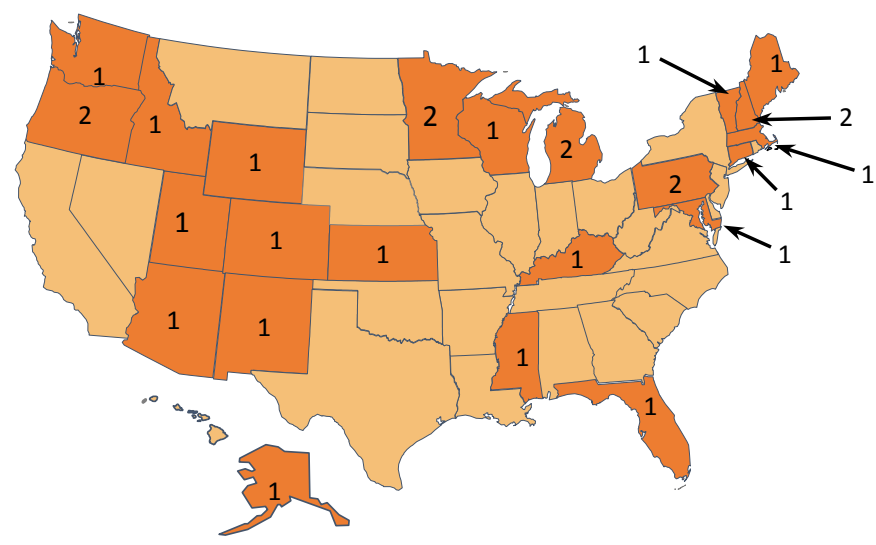

Survey respondents operate in the shaded states.

Please note: each power company executive was asked to indicate "the primary states where [their company has] operations." As some companies operate in multiple states, the figures in each state may not add up to the totals shown above. The companies may not have generating assets in every state shown.

\section{Scope}

Survey respondents were asked a series of questions about the following aspects of the Clean Power Plan:

- $\quad$ state versus federal compliance plans;

- $\quad$ preferred policy options for compliance plans;

- desirability of market-based approaches to compliance, including rate-based trading programs, mass-based trading programs, or a fee-based approach;

- adoption of rate-based versus mass-based targets; and

- multi-state compliance plans versus individual state plans (with and without interstate trading).

Survey respondents were not asked whether they support or oppose the Clean Power Plan. Respondents were asked to assume, for the purposes of the survey, that the Clean Power Plan will be adopted in its current form and provide their views on how it should be implemented.

Further information regarding the design of the survey can be found in Appendix $A$ to this Report. A full list of the survey questions is included in Appendix B. 


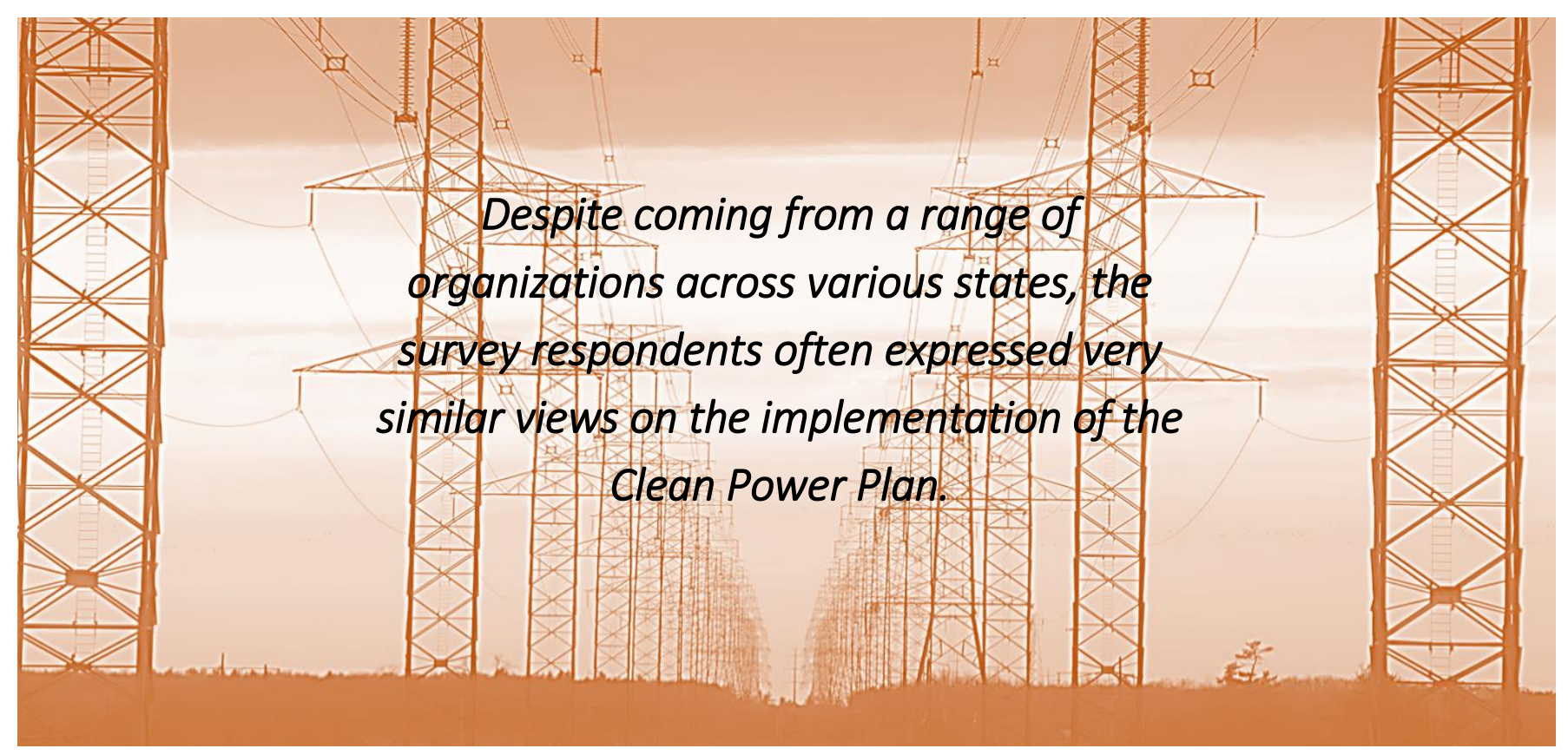




\section{State vs Federal Compliance Plans}

The proposed Clean Power Plan requires each state to develop and submit a plan outlining its strategy for reducing power sector emissions by summer 2016 or, if the plan will provide for multi-state compliance, by summer $2017 .{ }^{27}$ If the state is unable to complete its plan by that date, it may submit an interim plan, documenting its reasons for needing more time and outlining the measures it will take to prepare the final plan. ${ }^{28}$ That final plan will be due within one year of the original plan due date. ${ }^{29}$

Survey respondents noted the greater ease and flexibility in developing state-specific plans, giving them the opportunity to expand on state policies while respecting existing multi-state strategies.

After a state plan is submitted, EPA will have one year to approve the plan or send it back to the state for revision. ${ }^{30}$ If a state either declines to submit a plan, or does not receive approval by EPA, a federal compliance plan will be imposed on the state. ${ }^{31}$ Survey results show a clear preference for state developed compliance plans over federally developed plans.

In expressing support for state developed compliance plans, many survey respondents noted that the states are better able to understand their individual needs than EPA. As one power company executive observed, "the state[s] have a better understanding of their constraints and strength[s]." Another executive also noted that each state "is more familiar with region[al] energy operations and laws." The states can, therefore, develop compliance policies that are well suited to their unique conditions. In contrast, any federal plan developed by EPA may not reflect local conditions.

There is also some concern that a federally-developed plan may be less flexible and therefore more costly than any state plan. As discussed in section 1 above, under the proposed Clean Power Plan, the states are given considerable flexibility with respect to the emissions reduction strategies they can adopt. A state may, for example, reduce emissions through improvements at fossil fuel power plants or "beyond the fence line" options, such as renewable generation or energy efficiency, that reduce the dispatch of those plants.

Compared to the states, EPA may only be able to employ a limited range of emissions reduction strategies. EPA could not, for example, impose a renewable portfolio standard or energy efficiency measure in a state. Consequently, any EPA-developed plan would likely focus solely on reducing emissions from fossil fuel power plants. This could significantly increase the costs of complying with the Clean Power Plan. 
Despite this, some states are expected to forego developing their own compliance plans. ${ }^{32}$ In Oklahoma, for example, an Executive Order prohibits the state's environmental agencies from developing a compliance plan unless it is found to be legally required by the Oklahoma Attorney General or a court of competent jurisdiction. ${ }^{33}$ In Pennsylvania and West Virginia, legislation prevents environmental agencies from submitting a compliance plan without the approval of the legislature. ${ }^{34}$ Similar legislative measures, restricting the ability of state agencies to develop and/or submit a compliance plan, have also been considered in Texas. ${ }^{35}$ Notably however, our research suggests that those measures are not supported by most industry participants.

Just one power company executive surveyed favored development of a federal compliance plan over a state-developed plan. The only other support for a federal plan came from an environmental official, who indicated that the state wanted "a federal plan that is created ahead of time," but did not elaborate further on the scope of that plan (i.e., whether it would be applied directly to the state or serve as a model for a state-developed plan).

When asked whether they would prefer a state- or federally-developed compliance plan, 11 survey respondents selected "other," with many recommending development of a multi-state or regional compliance plan.

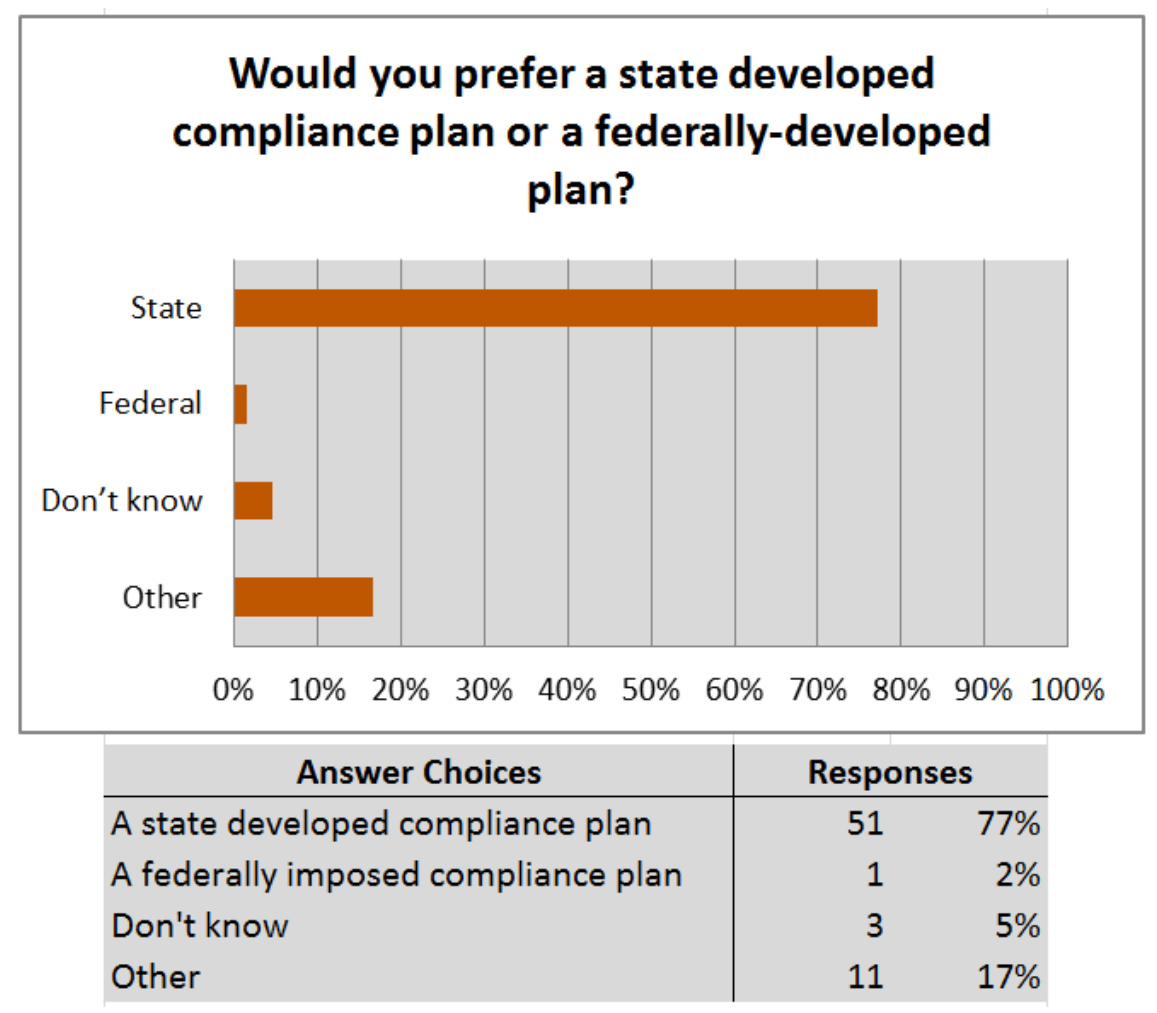




\section{State Plan Program Options}

States will have significant discretion in terms of the programs and policies they can use to comply with the Clean Power Plan. According to EPA, a state plan can include a combination of measures that reduce $\mathrm{CO}_{2}$ emissions at affected power plants, including emission limits or other measures that involve actions within the interconnected electricity system that reduce or avoid $\mathrm{CO}_{2}$ emissions.

Survey respondents were asked their views on different policy options for complying with the Clean Power Plan. The options

Most survey respondents agreed that state compliance plans should incorporate mass-based trading programs. Opinions varied, however, on what (if any) other policies should be adopted by the states.

The survey responses highlight the importance of allowing the states flexibility to adopt a variety of policies. included: (1) a mass-based trading program; (2) a rate-based performance standard; (3) an emissions fee approach; (4) a renewable portfolio standard; (5) an energy efficiency standard; or (6) other. Respondents were allowed to select multiple options.

Respondents expressed a strong preference for mass-based trading programs, under which fossil fuel power plants are required to hold credits or allowances for each ton of $\mathrm{CO}_{2}$ emitted. This approach was popular among power company executives, with 83 percent of those surveyed favoring mass-based trading. ${ }^{36}$ Similarly, mass-based trading was also supported by approximately 68 percent of state officials surveyed. ${ }^{37}$

Interestingly, the survey results indicate that there is broad support for mass-based trading across various states. Contrary to expectations, support was not limited to survey respondents in states controlled by Democratic governors, though it was somewhat higher in those states. Approximately 73 percent of officials surveyed in Democratically-controlled states supported mass-based trading programs. ${ }^{38}$ Those programs were supported by 62 percent of officials in Republican-controlled states. ${ }^{39}$

There was also some, albeit lower, support for other market-based compliance options. Use of a rate-based performance standard, allowing affected power plants to average their $\mathrm{CO}_{2}$ emissions, was supported by 30 percent of respondents. ${ }^{40} 26$ percent of respondents supported an emissions fee paid by affected sources for each ton of $\mathrm{CO}_{2}$ emitted. ${ }^{41}$ Notably, survey respondents did not view these market-based compliance options as mutually exclusive. 
Approximately 49 percent of respondents favoring mass-based trading also supported use of a rate-based performance standard and/or emissions fee approach. ${ }^{42}$

There was broad support for the use of complementary (beyond the fence line) policies to reduce emissions. Many survey respondents supported the adoption, in state compliance plans, of renewable portfolio standards which require a specified share of power to be supplied from renewable energy sources. This option was popular among state officials, with 61 percent of those surveyed indicating that renewable portfolio standards should be included in a state plan. ${ }^{43}$ Support was higher among officials in Democratic-run states (85 percent) than in Republican-run states (40 percent). ${ }^{44}$

Most state officials supporting the adoption of renewable portfolio standards also advocated the use energy efficiency standards. ${ }^{45}$ These standards, which require utility companies to produce a mandated level of power savings each year through the implementation of customer-side programs, were supported by 54 percent of state officials surveyed. ${ }^{46}$ Again, support was highest among officials in Democratic-run states (69 percent, compared to 40 percent in Republican-run states). ${ }^{47}$

This may be due to the fact that many state officials are already familiar with renewable energy and energy efficiency programs. 26 states had energy efficiency standards or goals as of March 2015. ${ }^{48}$ At that time, 29 states and the District of Columbia had renewable portfolio standards. ${ }^{49}$ The survey results suggest that many state officials would like to see these existing policies incorporated into, and expanded through, state compliance plans. Indeed, nearly threequarters of officials in states with existing renewable portfolio standards and/or energy efficiency measures stated that those policies should be included in a state plan. ${ }^{50}$ Inclusion of such policies may, however, be opposed by the power industry. Most power company executives surveyed opposed the inclusion of new or expanded renewable portfolio standards and energy efficiency measures in state compliance plans. ${ }^{51}$ Just 25 percent of executives surveyed supported the inclusion of such policies. ${ }^{52}$ 


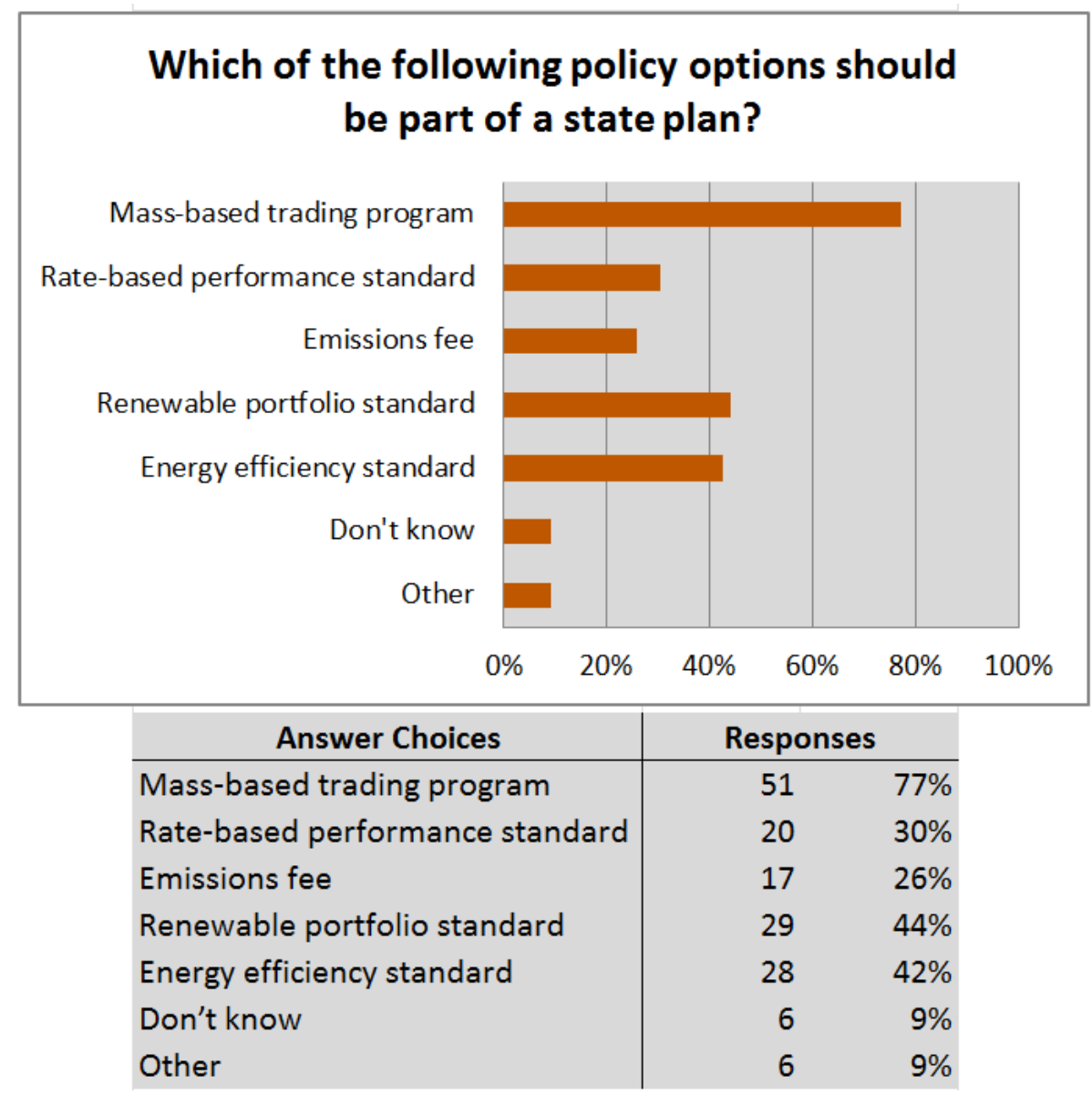

Overall, the survey responses highlight the importance of allowing states flexibility in designing their compliance plans. 65 percent respondents indicated that, in complying with the Clean Power Plan, states should rely on at least two policy options. ${ }^{53} 38$ percent of respondents supported the use of three or more policies. ${ }^{54}$ Thus, it seems likely that many states will adopt a portfolio approach, relying on several policies to comply with the Clean Power Plan. This could help to lower the cost of emissions reductions. As one industry consultant observed, using various policies "will provide diversity and economically efficient compliance." 


\section{Regulatory Options}

States have two basic options for regulating $\mathrm{CO}_{2}$ emissions from power plants:

(1) states may establish $\mathrm{CO}_{2}$ emissions limits that must be met by each power plant on a stand-alone basis, without the option to trade or average emissions; or

(2) states may adopt a market-based approach that provides for the averaging or trading of emissions across power plants. ${ }^{55}$

One example of a market-based approach is mass-based trading, whereby affected power plants must hold credits for each ton

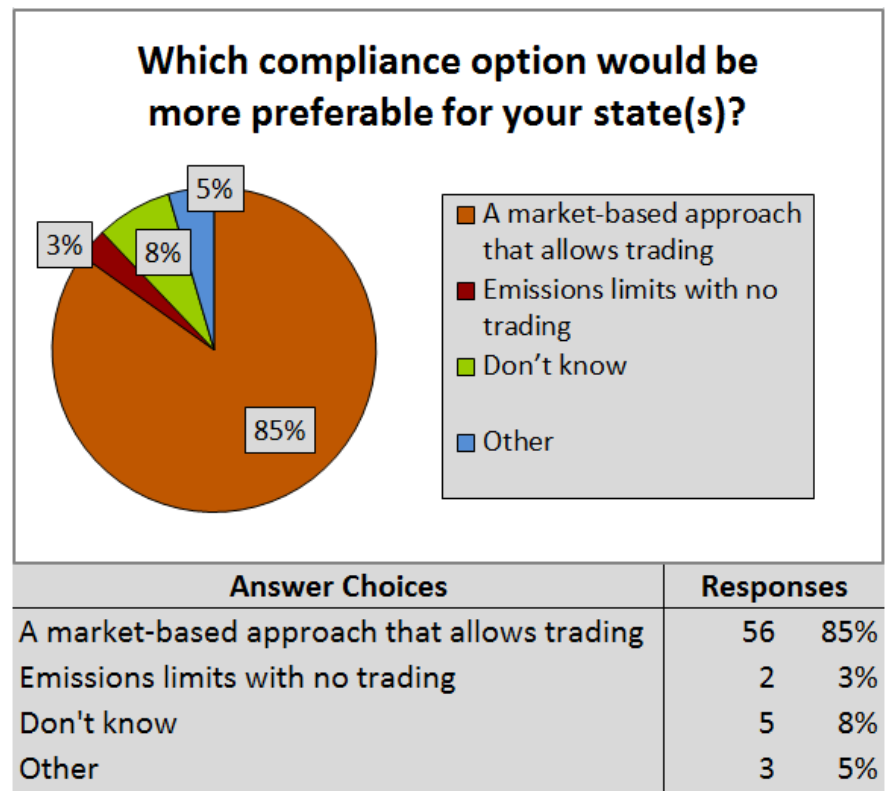

of $\mathrm{CO}_{2}$ emitted. Another similar approach is rate-based trading, whereby power plants must hold credits for all $\mathrm{CO}_{2}$ emissions in excess of a specified target. A state may award credits to power plants with emissions below the target, including zero-emitting renewable energy units. Those units could then sell credits to other power plants with emissions exceeding the target.

An emissions fee would also be considered a market-based mechanism. Under this approach, the state would set a dollar amount - the fee - which power plants must pay for each ton of $\mathrm{CO}_{2}$ emitted. Any revenues collected through the fee could be invested in energy efficiency or other programs to reduce emissions. Alternatively, the revenues could be redistributed to consumers to offset higher prices.

These types of market-based approaches were favored by most survey respondents. Just two respondents favored an approach that imposes limits on individual power plants with no opportunity to trade or average emissions. Interestingly, both of those respondents were utility regulator staff from Republican-controlled states.

Survey respondents were asked to indicate which market-based approach they prefer out of mass-based trading, rate-based trading, and an emissions fee. A majority of respondents (68 percent) preferred mass-based trading, arguing that such an approach is simple to implement and facilitates regional cooperation. ${ }^{56}$ As one industry consultant observed, a mass-based trading program is "[e]asier for states to administer [than other market-based approaches] and can be designed easily to coordinate with other states to capture cost-effective compliance 
options" across the region. A number of respondents also noted that this approach is proven, with many states already participating in some kind of mass-based program. Additionally, some indicated that a mass-based program could help to reduce the costs faced by electricity suppliers and customers, as well as generate revenues for the state.

Several respondents indicated that rate-based trading introduces greater complexity and is likely to be more controversial than a mass-based approach. This view is not, however, universal. Approximately 11 percent of survey respondents chose rate-based trading as their preferred approach. ${ }^{57}$ The majority of supporters were state officials. ${ }^{58}$ Just one power company executive preferred rate-based trading over a mass-based approach. The executive indicated that, unlike a mass-based approach, rate-based trading does not cap state-wide emissions. This was also emphasized by a state official, who noted that there is a perception that a mass-based approach may preclude future growth.

Although 17 survey respondents expressed support for the use of an emission fee (alongside other policies) in state compliance plans, none identified this as their preferred approach. Several respondents expressed concern that the fee-based approach is likely to be highly complex, noting that state policy-makers may find it difficult to select an appropriate fee. Thus, according to one industry consultant, "[t]he fee-based approach may take many iterations to get the desired level of emissions reductions."

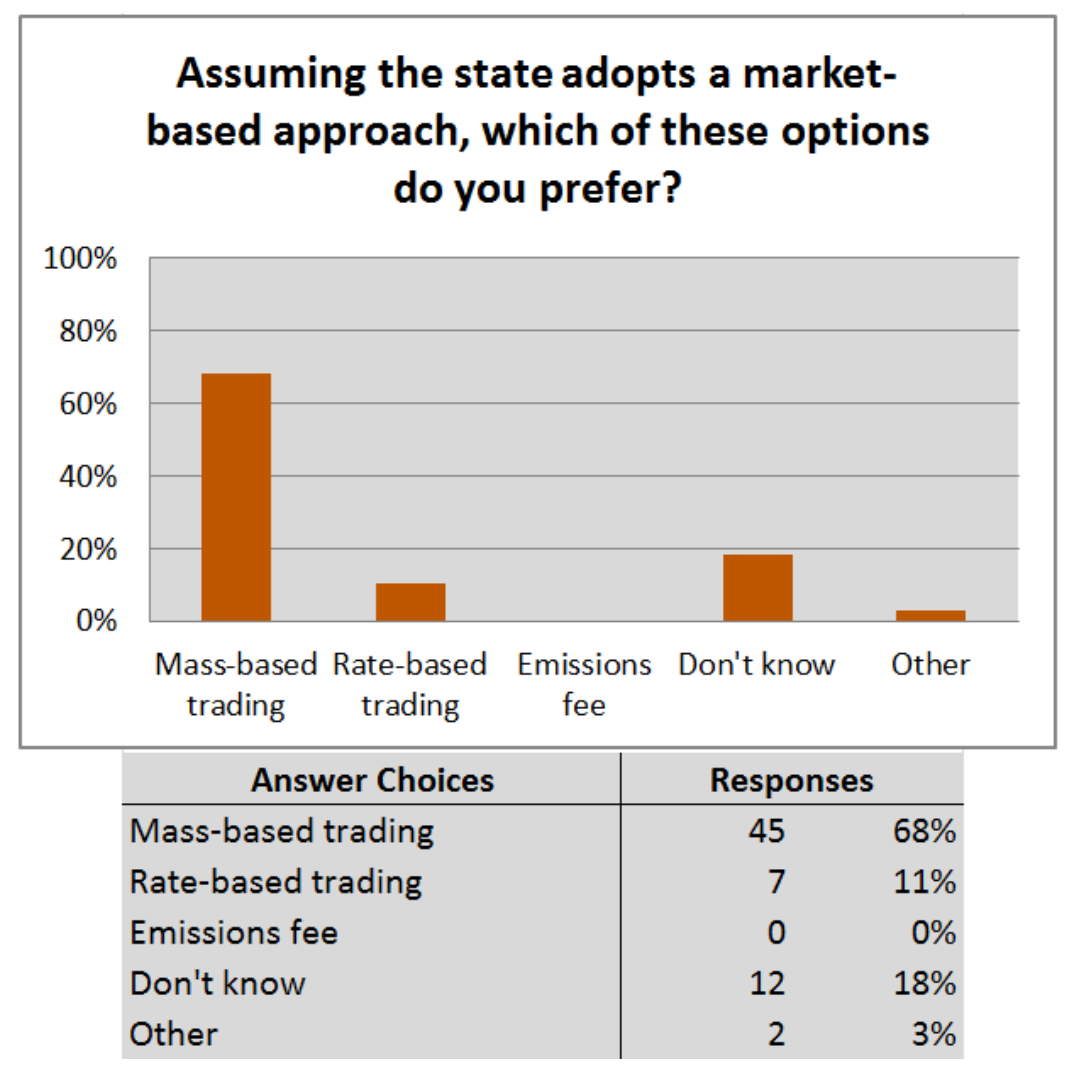




\section{RATE-BASED vS MASS-BASEd TARGETS}

States may select either a rate-based emissions target-expressed in pounds of $\mathrm{CO}_{2}$ per $\mathrm{MWh}-$ or a mass-based target-expressed in tons of $\mathrm{CO}_{2}$ per year - in complying with the Clean Power Plan. ${ }^{59}$ For example, for Texas, EPA proposed a rate-based target of $791 \mathrm{lbs} / \mathrm{MWh}$ by $2030 .{ }^{60}$ The state is, however, given the option of converting that target into a mass-based form. EPA has issued draft guidelines outlining the methodology to be used by states in converting their emissions targets. ${ }^{61}$ Applying this methodology, the mass-based target for Texas would be 135.9 million metric tons of $\mathrm{CO}_{2}$ by $2030 .{ }^{62}$

Survey respondents were asked which type of emissions target they prefer. Approximately 64 percent of respondents expressed a preference for mass-based targets.

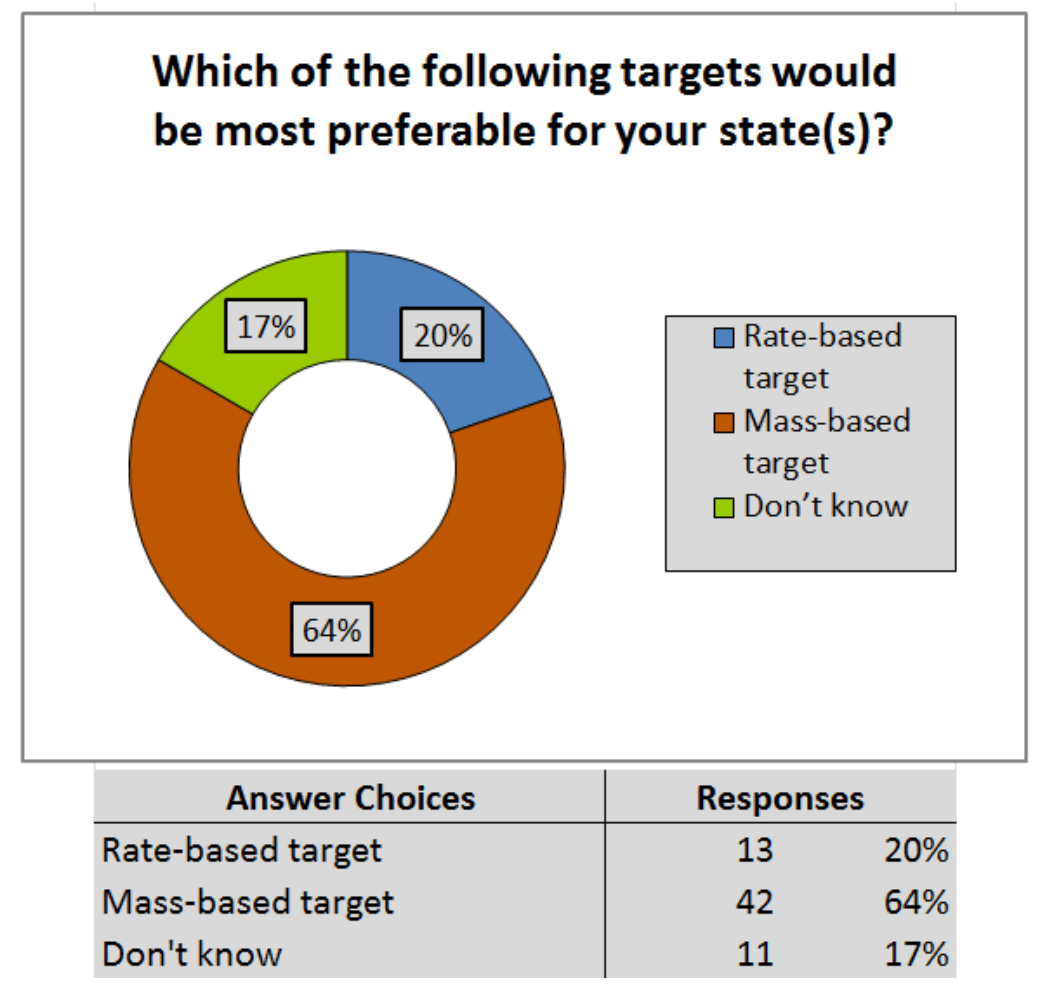

Many survey respondents noted that mass-based targets are likely to be easier to implement than rate-based targets. This is particularly true where a state wishes to use a mass-based trading program. As one industry consultant noted, "states [may] elect a mass-based budget which could be combined with those of other states" and then achieved through trading.

Several respondents also indicated that states may find it easier to track compliance with a mass-based target. This is because, with a mass-based target, a state would simply need to monitor the total $\mathrm{CO}_{2}$ emissions from affected power plants. In contrast, states using a rate- 
based target would have to determine total emissions from affected power plants in the state and divide that number by the MWh of electricity produced in the state by affected power plants and other qualifying sources (e.g., renewable and nuclear energy projects, and energy efficiency strategies).

Notwithstanding the above, support for mass-based targets was not universal. Approximately 20 percent of respondents favored the use of rate-based targets over their mass-based equivalents. While some of these respondents indicated a willingness to explore mass-based targets, others expressed concern that a mass-based target would limit electric sector growth, be difficult to calculate, or be less favorable to the state. As one state environmental official observed, the "decision [of which target to use is] influenced greatly by the rate to mass conversion formula. Currently, [the proposed formula] is not very favorable for a mass target."

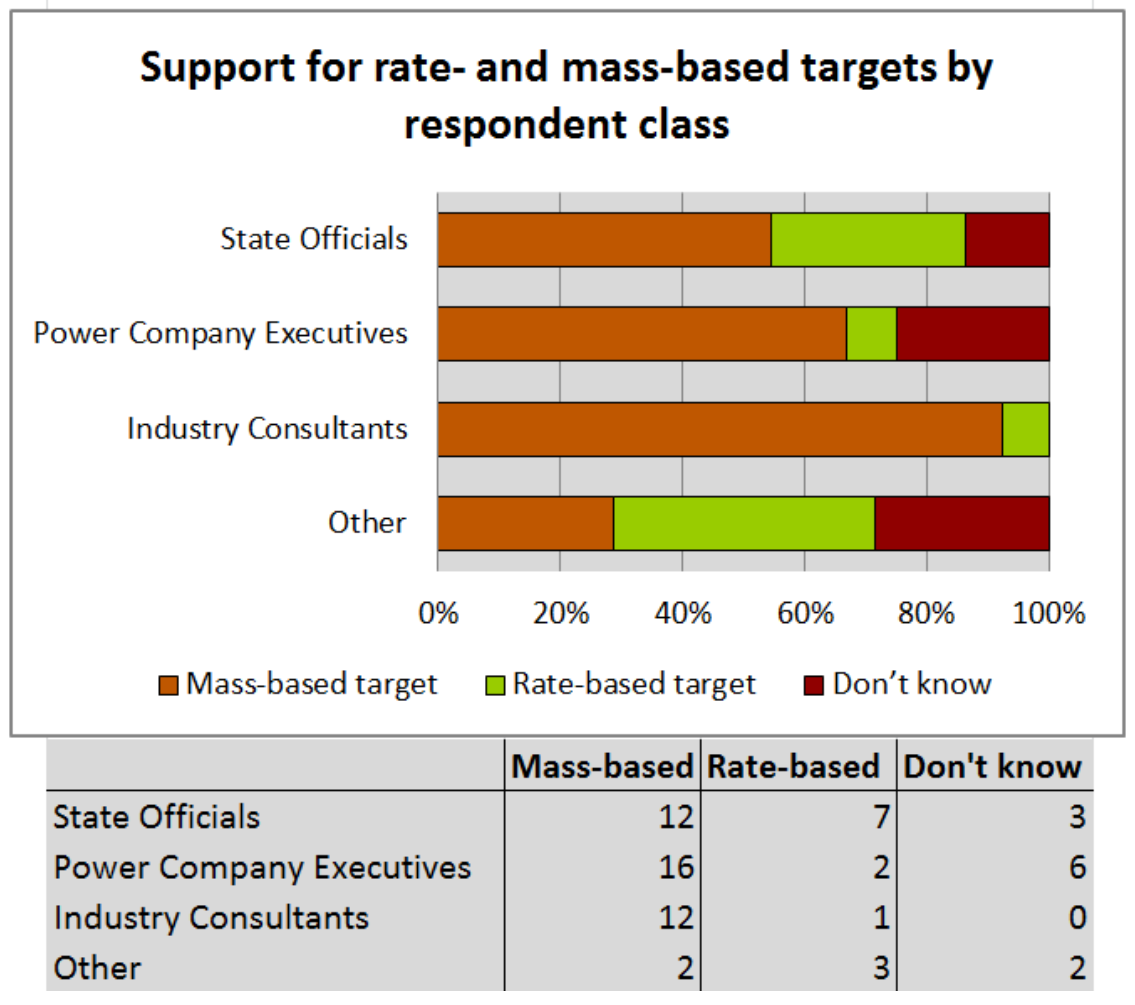




\section{Multi-state Compliance}

EPA is proposing to give states the choice of submitting an individual compliance plan or a multi-state compliance plan. A multi-state plan may be developed by states that wish to combine their individual emissions reduction targets and assume joint responsibility for operating programs to meet the combined target. With a multi-state plan, affected sources within the participating states would be able to trade emissions credits, renewable energy credits, or energy efficiency credits across state lines. ${ }^{63}$ Stakeholders have also suggested that states could develop individual state plans that still allow for trading across

\section{Which of the following would be most preferable for your state(s)?}

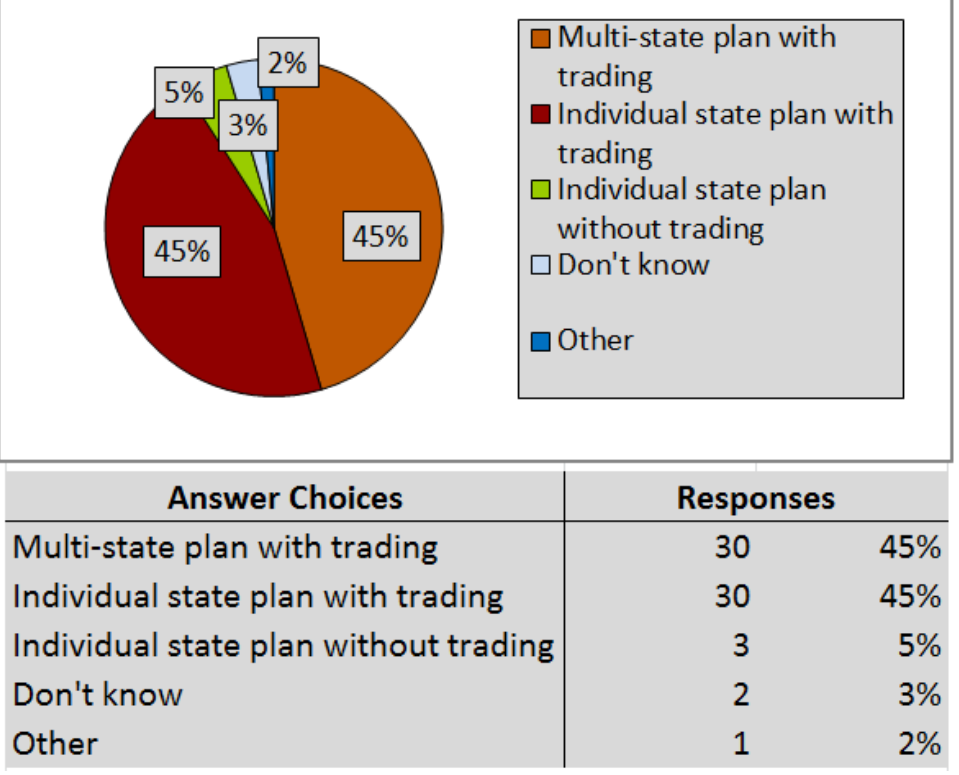

state lines even without a formal multi-state agreement. ${ }^{64}$

Survey respondents were asked to indicate what level of state coordination they preferred. Most respondents supported an approach that allows some sort of trading of emissions or other credits across state lines. Just three respondents - two state officials and one power company executive - supported adoption of an individual state plan with no provisions for trading with other states. This is hardly surprising given economic modeling suggesting that interstate trading may significantly reduce the costs of complying with the Clean Power Plan. ${ }^{65}$

The respondents supporting trading were equally divided between those who favored multistate plan and those who favored individual state plans allowing trading. Several respondents indicated that individual state plans may be easier to develop and implement, avoiding the need for complex negotiations between states. Moreover, the development of a multi-state plan may face political opposition, particularly in those states with lower compliance costs than their neighbors. These states may be reluctant to participate in regional programs due to concerns over higher costs. 
Nevertheless, joint plans may be appropriate for some states, including those currently participating in regional programs. For example, research suggests that states participating in the Regional Greenhouse Gas Initiative (RGGI) - a market-based cap-and-trade program for $\mathrm{CO}_{2}$ emissions in the north east - may find it advantageous to develop a joint compliance plan which builds on the existing programs. ${ }^{66}$ Perhaps for this reason, a number of survey respondents from RGGI states expressed support for multi-state compliance plans. 


\section{INTERSTATE TRADING OPTION}

Some economists suggest that there are potential cost savings for states in developing multistate trading mechanisms. ${ }^{67}$ The ability of each state to reduce power sector $\mathrm{CO}_{2}$ will vary depending on several factors, including its existing generation mix and the actions it has already undertaken to reduce emissions. A state that is already primarily served by natural gas generating systems may find it difficult to reduce emissions by re-dispatching existing resources, increasing compliance costs. In contrast, a state with the ability to expand low cost natural gas and/or the potential to develop renewable energy sources may face lower compliance costs. In this situation, multistate trading would likely produce cost savings as the low-cost state can reduce emissions below its target and sell those reductions to the higher cost state.

Given the potential for cost savings, it is perhaps unsurprising that the majority of survey respondents support multistate trading. When asked how important it is for states to allow multistate trading, 73 percent of respondents indicated that it is "very important" and a further 21 percent replied that it is "somewhat important."

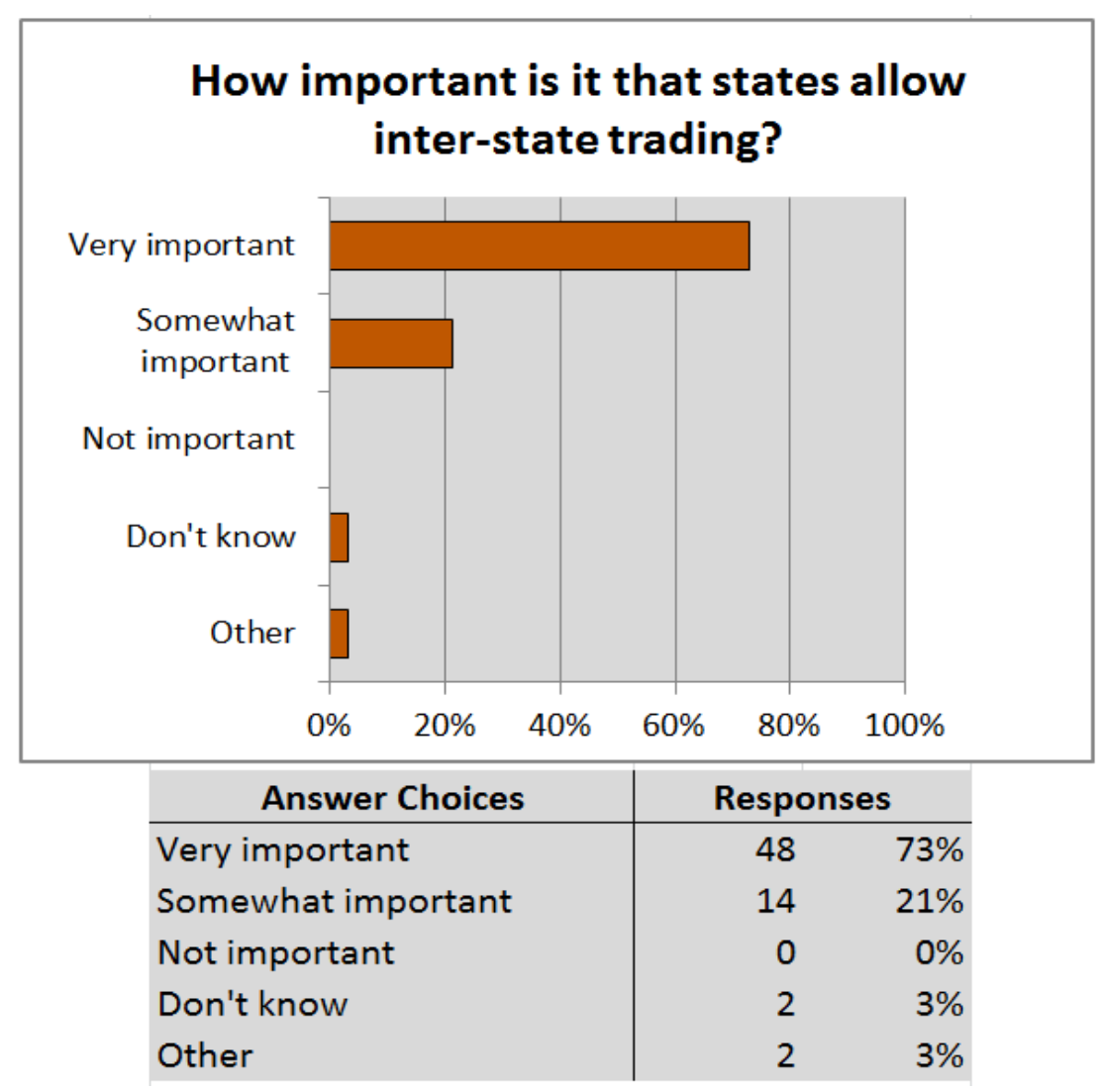




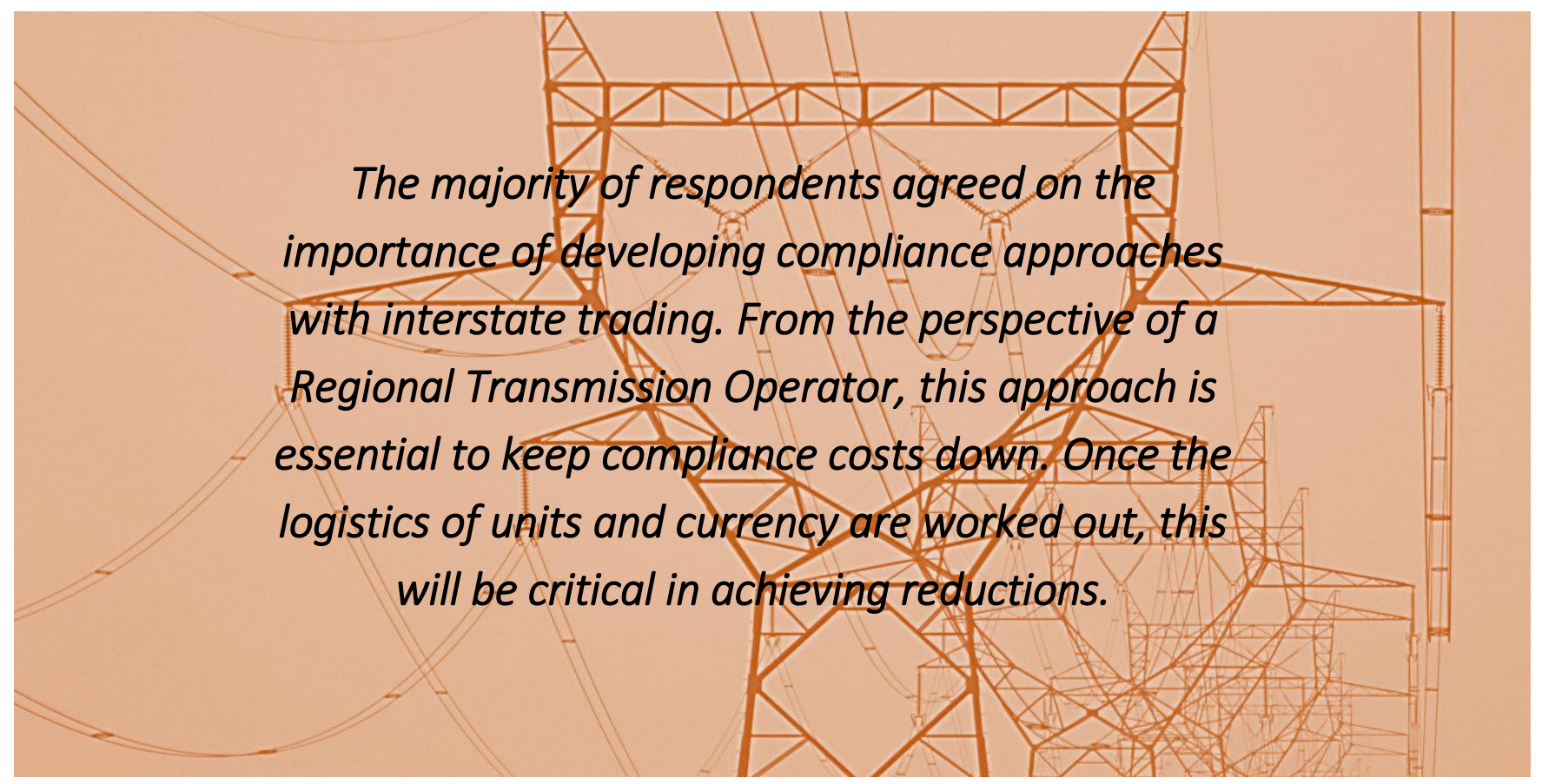




\section{CONCLUSION}

In June 2014, EPA published its draft Clean Power Plan, aimed at reducing $\mathrm{CO}_{2}$ emissions from existing fossil fuel power plants. The Plan is expected to be finalized in summer of 2015. Once this occurs, the states will then develop their own compliance plans, outlining strategies for reducing power sector emissions. The states will likely have significant discretion in terms of the emissions reductions strategies they can adopt. Various strategies have been proposed and are currently being debated by states, industry leaders, environmental groups, and public citizens.

To help inform this debate, from April to June 2015, The University of Texas at Austin conducted a survey on key issues relating to the Clean Power Plan. 66 respondents participated in the survey. They included power company executives, industry consultants, state officials, and RTO staff. Interestingly, while the survey respondents came from a range of organizations across various states, they often expressed very similar views on the Clean Power Plan.

Survey respondents were not asked whether they support or oppose the Clean Power Plan. Rather, the survey focused primarily on issues relating to implementation of the Plan. Key findings from the survey include:

- Most survey respondents favored development of state compliance plans over federally-developed plans.

- The majority of respondents supported the use of mass-based trading programs. Support for other policies, including renewable portfolio standards and energy efficiency measures, varied by respondent class.

- Respondents expressed strong support for market-based compliance options. When asked to choose between different market-based options, most respondents expressed a preference for mass-based trading, with a smaller number preferring rate-based trading.

- The bulk of respondents supported adoption of mass-based emissions targets in place of the rate-based targets proposed by EPA.

- There was broad support among respondents for interstate cooperation on the Clean Power Plan. 


\section{Appendix A: Survey Methodology}

This analysis was developed from survey responses collected over a nine-week period from April 15 to June 19, 2015. Most survey responses were collected through telephone interviews. Respondents who could not be contacted by telephone were sent an email asking them to complete the survey online. Responses received through the online survey accounted for 30 percent of total responses. ${ }^{68}$

The survey was administered by eight graduate students from the School of Law, the McCombs School of Business, and the LBJ School of Public Affairs at The University of Texas at Austin. Industry consultants M.J. Bradley \& Associates LLC assisted with the design of the survey, briefed the students on the details of the Clean Power Plan, and helped to encourage participation in the survey.

Students attempted to contact 300 people by phone and/or email. Of those contacted, 70 people agreed to participate in the survey. However, only 66 valid responses were received. The remaining four responses were incomplete and have therefore been excluded from the results.

Survey respondents were identified based on the contacts listed in public comments to EPA in the Clean Power Plan docket, on-line directories of state energy and environmental officials, and outreach to industry experts. Students only surveyed respondents that declared themselves to be "very familiar with the Clean Power Plan" or "somewhat familiar with the Clean Power Plan". Respondents indicating that they had only limited or no knowledge of the Clean Power Plan was asked to nominate another person within their organization to participate in the survey.

At the outset of the survey, the students emphasized that:

- Participation in the survey will be kept confidential.

- The results will be published in a public report, but only in an aggregate, summary form.

- Our goal with the survey is to elicit the views and opinions of experts on several key issues facing state policymakers as they implement the greenhouse gas rule.

- We are not asking participants whether they support or oppose the plan or their views on climate change in general.

- We assume for the purpose of the survey that EPA and the states will move forward with the greenhouse gas standards and we are interested in your opinions about how the policy should be implemented. 
After this introduction, each respondent was asked to provide basic demographic information, including his/her name, title, and organization. The respondent was then asked six multiple choice questions designed to elicit his/her views on key issues relating to implementation of the Clean Power Plan. Following each question, the respondent was given the option of providing additional comments regarding the targeted issue.

A full list of the survey questions is provided in Appendix B. 


\section{Appendix B: Survey Questions}

\section{Introduction}

Hello, and thank you for taking the time to participate in our survey! This survey is being conducted on behalf of the Kay Bailey Hutchison Center for Energy, Law, and Business at The University of Texas at Austin. We are conducting a brief survey about attitudes towards the U.S. Environmental Protection Agency's plan to regulate $\mathrm{CO} 2$ emissions from power plants under section 111(d) of the Clean Air Act, also known as the Clean Power Plan. Our aim is to get in touch with key stakeholders from across the country who will be affected by the rule.

This survey should take only about 10 minutes to complete.

To start, would you say you are:

$\ulcorner$ Very familiar with the Clean Power Plan

$\odot$ Somewhat familiar with the Clean Power Plan

$\triangle$ Have only limited knowledge of the plan

$\sigma$ Are not familiar, have no knowledge of the plan

If limited or no knowledge: Can you suggest someone else within your organization who might be more familiar with the rule so we can include their opinions?

\section{Next Steps}

Before you begin, we want to emphasize that:

- Your participation in the survey will be kept completely confidential.

- The results will be published in a public report later this year but only in an aggregate, summary form. We won't publish results by company or state agency.

- Our goal with the report is to elicit the views and opinions of experts, like yourself, on several key issues facing state policymakers as they implement the greenhouse gas rule.

- We are not asking participants whether they support or oppose the plan or their views on climate change in general, so as we go through these questions, please keep in mind that we are looking for your ideas as they relate to the questions, not your opinions about the general merits of the standards.

- We assume for the purpose of the survey that EPA and the states will move forward with the greenhouse gas standards and we are interested in your opinions, and the opinions of others like you, about how the policy should be implemented. 


\section{Interviewee Information}

Please confirm your full name for internal purposes.

\section{Background Questions}

First, a few background questions.

What is your title?

Would you describe yourself as:

$\triangle$ A power company executive

$\triangle$ A utility commission staff employee

$\odot$ A state environmental official

$\ulcorner$ A state energy official

$\varnothing$ An industry consultant

$\curvearrowleft$ Other (please specify)

If a power company executive:

What type of company do you work for?

$\odot$ An investor owned utility

$\odot$ A municipal utility

$\triangle$ A cooperative

$\triangle$ A merchant generator

$\sqsubset$ Other (please specify)

What are the primary states where you have operations?

Does your company own or operate any fossil-fired power plants that would potentially be regulated under the rule?
$\circ$ Yes
$\subset$ No
$\subset$ Not sure

If a state energy or environmental official: 
What state do you work for?

\section{Question 1}

Now we will address issues specific to the $111(\mathrm{~d})$ rule, also known as the Clean Power Plan. We have provided a Comments section at the bottom of each question for any additional notes you would like to add regarding the targeted issue.

Once the EPA has finalized the 111(d) rule later this summer, states will need to develop a plan to comply with the rule, including policies or measures to limit $\mathrm{CO} 2$ emissions. If a state fails to submit or develop an approvable plan, EPA can enforce a Federal Plan.

Which of these options do you think would be most preferable for your state or states?

$\varnothing$ A state developed compliance plan

$\triangle$ A federally imposed compliance plan

Not sure

$\ulcorner$ Other (please specify)

\section{Comments}

\section{Question 2}

States will have significant discretion in terms of the programs and policies they can use to comply with the Clean Power Plan.

According to EPA, a state plan can include a combination of measures that reduce $\mathrm{CO} 2$ emissions at affected power plants through the application of emissions limits as well as measures that involve actions within the interconnected electricity system that reduce the utilization of affected power plants and therefore avoid $\mathrm{CO} 2$ emissions.

In your opinion, which of the following options do you think should be part of a state plan? You can select multiple options.

A mass-based trading program

$\triangle$ A rate-based performance standard (Ib/MWh)

$\sigma$ An emissions fee approach

$\checkmark$ A renewable portfolio standard

$\checkmark$ An energy efficiency standard

$\ulcorner$ Not sure 
$\ulcorner$ Other (please specify)

Comments

\section{Question 3}

States have two basic options for regulating emissions from power plans.

One option would be for states to adopt some type of market-based regulatory approach wherein power plants could average their emissions rates or trade emission credits with other regulated power plans. A fee-based approach would also be considered a market-based approach.

Another option would be for states to adopt an approach that imposes limits on the $\mathrm{CO} 2$ emissions of individual power plants with no trading or averaging.

Which of these two potential compliance options do you think would be most preferable for your state or states?

$\triangle$ A market-based approach, for example, one that allows affected entities to trade or average their emissions.

$\subset$ An approach that imposes limits on individual plants with no trading or averaging

Not sure

$\circ$ Other (please specify)

\section{Comments}

\section{Question 4}

Assuming that a state does adopt a market-based regulatory approach on emissions from affected power plants, which of these options do you think would be most preferable for your state or states?

$\triangle$ A rate-based trading program

A mass-based trading program

$\triangle$ A fee-based approach

$\ulcorner$ Not sure

$\ulcorner$ Other (please specify) 
Why do you favor this option?

Why are you opposed to the other option?

\section{Comments}

\section{Question 5}

The EPA plans to allow states to select either a rate-based target - expressed in pounds per megawatt hour - or a mass-based target - expressed in tons per year.

Note that this is a separate decision from the regulatory approach used to comply with the target. Under a rate-based target, a state would track both its $\mathrm{CO} 2$ emissions and MWhs of generation. Under a mass-based target, it would track its emissions relative to the target.

Recognizing that the final standards may change between the proposed and final rule, which of these two options do you think would be most preferable for your state or states?

$\subset$ A rate-based target

$\triangle$ A mass-based target

Not sure

$\circ$ Other (please specify)

Why do you favor this option?

Why are you opposed to the other option?

\section{Comments}

\section{Question 6}

There are several options states might choose to develop their compliance plans vis-à-vis other states or regions.

- States could choose to develop a coordinated plan that allows trading or averaging of emissions across state lines. 
- A state could develop an individual plan that allows affected sources within the state to trade emissions credits, renewable energy credits, or energy efficiency credits across state lines even without a formal multi-state agreement.

- Or, states could simply comply with their individual performance goal without any multistate trading.

Which of the following options do you think would be most preferable for the state or states you represent / operate in?

$\triangle$ A multi-state plan with coordinated programs or policies across state lines

$\sigma$ An individual state plan that still preserves the option to trade emissions or renewable or other credits across state lines

$\odot$ An individual state plan with no provisions for trading with other states

Not sure

$\ulcorner$ Other (please specify)

\section{Comments}

\section{Question 7}

Some economists have suggested that there would be potential cost savings to states by utilizing trading mechanisms, allowing broader compliance flexibility.

How important do you think it is that states develop compliance approaches that allow interstate trading?

$\sigma$ Very important

Somewhat important

$\ulcorner$ Not important

$\ulcorner$ Not sure

$\ulcorner$ Other (please specify)

\section{Comments}




\section{Closing}

Those are all the questions we have for you. Thank you for taking the time to participate in this survey and for sharing your opinions on the Clean Power Plan. Again, remember that your participation in this survey will remain confidential.

If you would like to receive a copy of the final report when it is released, please provide us the best e-mail address to send it to below.

Thanks again, we appreciate your participation.

Email address 
${ }^{1}$ Carbon Pollution Emission Guidelines for Existing Stationary Sources: Electric Utility Generating Units, 79 Fed. Reg. 34830 (proposed Jun. 18, 2014) (to be codified at 40 C.F.R. pt. $60)$.

2 U.S. Energy Information Administration, What is U.S. electricity generation by energy source?, FREQUENTLY ASKED QUESTIONS, http://www.eia.gov/tools/faqs/faq.cfm?id=427\&t=3 (last updated Mar. 31, 2015).

3 U.S. Energy Information Administration, MAy 2015 Monthly EnERgy ReVIEW, 105 (2015), available at http://www.eia.gov/totalenergy/data/monthly/pdf/mer.pdf (indicating that coal-fired generation produced 1,978,301 million kilowatt hours of electricity in 2004 and 1,585,697 million kilowatt hours in 2014).

${ }^{4} / d$. (indicating that natural gas-fired generation produced 710,100 million kilowatt hours of electricity in 2004 and 1,121,928 million kilowatt hours in 2014, while non-hydroelectric renewable energy sources supplied 83,068 million kilowatt hours of electricity in 2004 and 281,059 million kilowatt hours in 2014).

${ }^{5}$ Carbon Pollution Emission Guidelines for Existing Stationary Sources: Electric Utility Generating Units, 71 Fed. Reg. at 34830.

${ }^{6} / d$. at 34832 .

${ }^{7} / d$. at 34895. It should be noted that emissions reductions targets have not been set for Vermont or Washington D.C. Those jurisdictions have been excluded from the Clean Power Plan as they do not have any fossil fuel power systems.

${ }^{8} / d$. at 34851.

${ }^{9}$ Endangerment and Cause or Contribute Findings for Greenhouse Gases Under Section 202(a) of the Clean Air Act, 75 Fed. Reg. 66496 (Dec. 15, 2009) (40 CFR Ch. 1). See also, Carbon Pollution Emission Guidelines for Existing Stationary Sources: Electric Utility Generating Units, 71 Fed. Reg. at 34843.

10 Standards of Performance for Greenhouse Gas Emissions from New Stationary Sources: Electric Utility Generating Units, 79 Fed. Reg. 1430 (proposed Jan. 8, 2014) (to be codified at 40 C.F.R. pt. 60, 70, 71, and 98).

11 U.S. Environmental Protection Agency, Key Dates: Cutting Carbon Pollution from Power Plans, 1 (2014), available at http://www2.epa.gov/sites/production/files/201501/documents/20150107fs-key-dates.pdf. 
12 U.S. Environmental Protection Agency, Fact Sheet: Clean Power Plan \& Carbon Pollution Standards Key Dates, CARBON PolLuTION STANDARDS, http://www2.epa.gov/carbon-pollutionstandards/fact-sheet-clean-power-plan-carbon-pollution-standards-key-dates (last updated Jan. 7,2015 ) (indicating that EPA will issue carbon pollution standards for new and existing power plans in summer 2015).

1340 C.F.R. $\S 60.22$ (2015).

${ }^{14}$ Clean Air Act, §§ 111(a)(1), 111(d)(1)(A); 42 U.S.C. §§ 7411(a)(1), 7411(d)(1)(A) (2015). See also 40 C.F.R. $\S 60.22(b)(5)(2015)$.

${ }^{15}$ Carbon Pollution Emission Guidelines for Existing Stationary Sources: Electric Utility Generating Units, 71 Fed. Reg. at 34895

16 Id. at 34851.

17 Id. at 34894.

18 ld. at 34835.

19 Id. at $34835,34837$.

${ }^{20}$ ld. at 34901-34902.

${ }^{21} / d$.

22 Id. at $34833,34900$.

${ }^{23}$ Where a state develops an individual plan, that plan will be due one year after finalization of the Clean Power Plan. Where a multi-state plan is developed, that plan will be due two years after finalization of the Clean Power Plan.

${ }^{24} / d$. at 34915 (indicating that "each state must submit a plan to the EPA by June 30, 2016, which is more than one year after the expected finalization date of the emission guidelines. However, if a state is unable to complete its plan within this time, it may apply for an extension).

${ }^{25}$ In this report, the term "state official" is used to refer to state environmental officials, state energy officials, and utility regulatory staff.

2617 of the 24 power company executives surveyed reported that their company owned or operates fossil fuel power plants. Three executives surveyed reported that their company does not own or operate fossil fuel power plants. Another four executives declined to provide this information. 
27 Id. at 34851.

$28 / d$. at 34851.

${ }^{29} / d$. at 34851.

${ }^{30} / d$. at 34916, 34951.

31 Id. at 34951.

32 Andrew Childers and Anthony Adragna, McConnell Pushes 'Just Say No' Campaign Against EPA's Clean Power Plan, Bloomberg BNA, Mar. 5, 2015, http://www.bna.com/mcconnellpushes-say-n17179923648/ (indicating that between 15 and 20 states could forgo developing their own compliance plans). Compare however, Naveena Sadasivam, 49 States Making Plans for EPA Carbon Rule-Even the Ones that Hate It, InsideCLIMATE NEWS, Jun. 3, 2015, http://insideclimatenews.org/news/03062015/clean-power-plan-coal-obama-49-statesmaking-plans-epa-carbon-rule-even-ones-hate-it (stating that 49 states are expected to develop their own compliance plan).

33 Okla. Exec. Order No. 2015-22 (Apr. 28, 2015), https://www.sos.ok.gov/documents/executive/978.pdf.

342014 Pa. Act 175; 2015 W. Va. HB 2004.

35 Tex. S.B. 1761, 84th Leg., R.S. (2015); Tex. S. Con. Res. $27,84^{\text {th }}$ Leg., R.S. (2015).

${ }^{36}$ Mass-based trading programs were supported by 20 of the 24 power company executives.

37 Mass-based trading programs were supported by 19 of the 28 state officials surveyed.

38 Of the 13 state officials surveyed in Democratically-run states, 11 expressed support for mass-based trading programs.

39 Of the 15 state officials surveyed in Republican-run states, 8 expressed support for massbased trading programs.

${ }^{40}$ A rate-based performance standard was supported by 20 of the 66 survey respondents.

${ }^{41}$ An emissions fee was supported by 17 of the 66 survey respondents.

42 Of the 51 survey respondents supporting adoption of a mass-based trading program, 25 also supported adoption of a rate-based performance standard and/or emissions fee.

${ }^{43}$ Renewable portfolio standards were supported by 17 of the 28 state officials surveyed. 
${ }^{44}$ Of the 13 state officials surveyed in Democratically-run states, 11 supported the use of renewable portfolio standards. In comparison, only 6 of the 15 state officials surveyed in Republican-run states supported the use of renewable portfolio standards.

${ }^{45}$ Of the 17 state officials supporting renewable portfolio standards, 14 also supported energy efficiency measures.

${ }^{46}$ Energy efficiency measures were supported by 15 out of 28 state officials surveyed.

47 Of the 13 state officials surveyed in Democratically-run states, 9 supported the use of energy efficiency measures. In comparison, only 6 of the 15 state officials surveyed in Republican-run states supported use of energy efficiency measures.

48 North Carolina Clean Energy Technology Center, Database of State InCEntives for Renewables \& EfFiciency: Energy EfFiciency Resource StAndards (And GoAls) (2015), available at http://ncsolarcen-prod.s3.amazonaws.com/wp-content/uploads/2015/03/Energy-EfficiencyResource-Standards.pdf.

49 North Carolina Clean Energy Technology Center, Database of State Incentives for Renewables \& EfFiciency: RenewABle PoRTfolio StAndards (2015), available at http://ncsolarcenprod.s3.amazonaws.com/wp-content/uploads/2014/11/Renewable-Portfolio-Standards.pdf

50 Of the 28 state officials surveyed, 22 were from states with existing renewable portfolio standards or goals and 19 were from states with existing energy efficiency standards or goals. Of those, 16 supported the inclusion of renewable portfolio standards and/or energy efficiency measures in state plans.

5118 of the 24 power company executives surveyed indicated that renewable portfolio standards and energy efficiency measures should not be part of a state plan.

526 of the 24 power company executives surveyed supported the inclusion, in state plans, of renewable portfolio standards and/or energy efficiency measures.

53 The use of 2 or more policy options was supported by 43 survey respondents.

54 The use of 3 or more policy options was supported by 25 survey respondents.

${ }^{55}$ Carbon Pollution Emission Guidelines for Existing Stationary Sources: Electric Utility Generating Units, 79 Fed. Reg. at 34927.

5645 of the 66 survey respondents expressed a preference for mass-based trading programs.

577 of the 66 survey respondents expressed a preference for rate-based trading programs. 
584 of the 7 survey respondents supporting rate-based trading were state environmental or energy officials or utility regulator staff. The state officials supporting rate-based trading all came from Republican-controlled states, while the utility regulator staff came from Democraticcontrolled states.

59 Id. at 34837 .

60 Id. at 34895 .

61 U.S. Environmental Protection Agency, Translation of the Clean Power Plan Emission Rate-Based $\mathrm{CO}_{2}$ GoALS TO MASS-BASEd Equivalent (2014), available at http://www2.epa.gov/carbon-pollutionstandards/clean-power-plan-proposed-rule-translation-state-specific-rate-based-co2.

62 Id. at 14

${ }^{63}$ Carbon Pollution Emission Guidelines for Existing Stationary Sources: Electric Utility Generating Units, 79 Fed. Reg. at 34900.

64 See, for example, Jonas Monast et Al, Enhancing Compliance FleXibility Under the Clean Power Plan: A Common Elements Approach to Capturing Low Cost Emissions Reductions, (2015), available at https://nicholasinstitute.duke.edu/sites/default/files/publications/ni pb 15-01.pdf (arguing that "a state could develop an individual-state plan to meet its own emissions target...and allow [electric generating units] to transfer compliance credits among units within a state or among states that share common elements in their compliance plans"); THE NATIONAL ASSOCIATION OF Regulatory Utility Commissioners, Multistate Coordination Resources for Clean Power Plan COMPLIANCE: SAMPLE DOCUMENTS FOR CONSIDERATION (2015), available at http://www.naruc.org/ Publications/Multistate\%20111d\%20Coordination.pdf (noting that "[s]tates do not need to enter into a multi-state compliance plan with a joint target to benefit from talking and coordinating. A range of interactions is possible...[including] the transfer of emissions reductions between states that have individual-state plans and targets (not a multi-state plan to meet a joint target) when states have 'common elements' in their compliance plans").

65 See, for example, Martin T. Ross et Al., The Clean Power Plan: Implications of Three Compliance DECISIONS FOR U.S. STATES, 27 (2015), available at https://nicholasinstitute.duke.edu/sites Ldefault/files/publications/ni wp 15-02 full pdf.pdf.

${ }^{66}$ For a discussion of this issue, see Ecology AND ENVIRONMENT, INC. \& NATURAL Resources DefENSE Council, Regional Policies for Clean Power Plan Compliance: A Comparison of Leading Proposals (2014), available at http://www.dmme.virginia.gov/DE/LinkDocuments/VEP Update/Regional GHG Policy Comparison.pdf.

${ }^{67}$ RosS ET AL., supra note 65, at 27.

6820 valid responses were received through the online survey. 


\section{KBH Center for Energy, Law, and Business}

\section{EXECUTIVE COUNCIL}

Duke R. Ligon, Co-chair

Sam L. Susser, Co-chair

Linda L. Addison

James H. Clement, Jr.

Joseph C. Dilg

The Honorable Kay Bailey Hutchison

Rob L. Jones

Sylvia J. Kerrigan

James Lloyd Loftis

Jon P. Newton

Rad Weaver

\section{ADVISORY COUNCIL}

Matthew Acock

Juan M. Alcalá

S. Jack Balagia, Jr.

Karl Bayer

David J. Beck

Laura H. Beckworth

Jeff Civins

Lyn Clancy

John B. Connally, IV

James E. Cousar

Richard D. Deutsch

Harry Gee, Jr.

Pamela M. Giblin

R. Kinnan Goleman

Rene Gonzalez

Stephanie C. Hildebrandt

Monty Humble

The Honorable James R. Jones

David B. Kultgen

Diana Liebmann
The Honorable Tom G. Loeffler Joel H. Mack

W. James McAnelly, III Michael A. McConnell James C. Morriss, III

Suzanne Murray

Larry W. Nettles

Ashley T.K. Phillips

James M. Rhodes

The Honorable Arturo Sarukhán The Honorable Barry T. Smitherman

James M. Spellings, Jr.

Marcelo E. Tamez

Timothy J. Tyler

D. Marie Wagner

Robert C. Walters

Dick Watt

Roderick E. Wetsel

John F. Wombwell

Libin Zhang 